\title{
An improved noninvasive method for measuring heartbeat of intertidal animals
}

\author{
Nicholas P. Burnett ${ }^{1 *}$, Rui Seabra',3, Maurizio de Pirro ${ }^{4}$, David S. Wethey ${ }^{1}$, Sarah A. Woodin', Brian Helmuth ${ }^{1,5}$, \\ Mackenzie L. Zippay ${ }^{7}$, Gianluca Sarà ${ }^{6}$, Cristián Monaco ${ }^{1}$, and Fernando P. Lima ${ }^{1,2}$ \\ ${ }^{1}$ Department of Biological Sciences, University of South Carolina, Columbia, SC 29208 \\ ${ }^{2}$ CIBIO, Centro de Investigação em Biodiversidade e Recursos Genéticos, Universidade do Porto, Campus Agrário de Vairão, \\ 4485-661 Vairão, Portugal \\ ${ }^{3}$ Departamento de Biologia, Faculdade de Ciências da Universidade do Porto, R. Campo Alegre, s/n, 4169-007 Porto, Portugal \\ ${ }^{4}$ Accademia Mare Ambiente, Lungomare dei Navigatori 44, 58019 Monte Argentario, Italy \\ ${ }^{5}$ Marine Science Center, Northeastern University, Nahant, MA 01908 \\ ${ }^{6}$ Dipartimento di Ecologia, Università degli Studi di Palermo, Viale degli Scienze Ed. 16, 90128 Palermo, Italy
}

\begin{abstract}
Since its emergence two decades ago, the use of infrared technology for noninvasively measuring the heartbeat rates of invertebrates has provided valuable insight into the physiology and ecology of intertidal organisms. During that time period, the hardware needed for this method has been adapted to currently available electronic components, making the original published description obsolete. This article reviews the history of heartbeat sensing technology, and describes the design and function of a modern and simplified infrared heartbeat rate sensing system compatible with many intertidal and marine invertebrates. This technique overcomes drawbacks and obstacles encountered with previous methods of heartbeat rate measurement, and due to the sensor's small size, versatility, and noninvasive nature, it creates new possibilities for studies across a wide range of organismal types.
\end{abstract}

Heartbeat rate, or cardiac activity, has been shown to serve as an effective index for whole organism physiology for a variety of intertidal invertebrates including mollusks (Chelazzi et al. 2001; Helm and Trueman 1967; Marshall et al. 2011; Santini et al. 1999, 2000) and arthropods (Bini and Chelazzi 2006; Calosi et al. 2005; De Pirro et al. 1999a; Rovero et al. 2000; Styrishave et al. 2003; Ungherese et al. 2008). Quantifying this parameter under a variety of natural and experimental conditions can aid in understanding the general physiological responses of these organisms to abiotic stresses in the envi-

*Corresponding author: E-mail: burnettnp@berkeley.edu Current address: Department of Integrative Biology, University of California, Berkeley, CA 94720

\section{Acknowledgments}

This work was funded by Fundação para a Ciência e a Tecnologia (FCT) through the project PTDC/MAR/099391/2008, NSF (OCE0926581, OCE1039513, OCE1129401), and NASA (NNG07AF20G, NNX11AP77). R.S. and F.P.L were supported by FCT individual grants SFRH/BD/68521/2010 and SFRH/BPD/34932/2007, respectively. N.P.B. was supported by a Magellan Scholar Grant from the University of South Carolina. L. E. Burnett provided laboratory space and impedance sensors for the Callinectes experiments. G. A. Williams provided laboratory space for the Septifer experiments.

DOI 10.4319/lom.2013.11.91 ronment (Logan et al. 2012; Stillman and Somero 1996; Styrishave et al. 2003; Ungherese et al. 2008; Williams et al. 2011), biotic interactions (Rovero et al. 1999, 2000), and exposure to toxins (Chelazzi et al. 2004; Galloway et al. 2004; Halldórsson et al. 2008; Marshall et al. 2004). In particular, these data can improve our ability to predict the responses of species to changing environments such as increases in temperature or levels of pollution. Such predictions are particularly relevant for the intertidal zone where many species are thought to already live at or near their upper lethal limits of stress tolerance (Somero 2002).

Measuring cardiac activity of intertidal organisms has been a focus of research for many decades (Bayne et al. 1976; Braby and Somero 2006; Nicholson 2002; Pickens 1965). One of the first methods, which is still used, measures the changes of circulatory structures with electrical impedance. This is an invasive technique, which requires implanting electrodes in the pericardial cavity (Helm and Trueman 1967). Changes in the impedance between the electrodes are proportional to the change of the circulatory cavity or vessel during a heartbeat.

A more recently developed alternative to the impedance method uses an infrared (IR) light emitting diode (LED), which generates an electric signal that is electronically ampli- 
fied and filtered, coupled with a phototransistor detector (hereafter IR sensor). In the late 1980s, Depledge and Andersen (1990) devised a computer-aided physiological monitoring system (CAPMON) in which the average heartbeat frequency of the target animal was automatically computed via custommade hardware connected to a PC. This method was quickly adopted in marine and intertidal invertebrate physiology research because it was noninvasive, allowed for multiple cardiac activities to be measured simultaneously, could function in both air and water, and was capable of measuring continuously for long periods of time.

Studies using the CAPMON system have been confined to a relatively small group of investigators (Curtis et al. 2000; Morritt et al. 2007; Santini et al. 1999; Styrishave et al. 2003). The CAPMON design has however been regularly upgraded to be compatible with the evolving electronics technology and modified, for example, to be connected to any data logger or oscilloscope. The original hardware described by Depledge and Andersen (1990) is difficult to assemble using parts currently available from electronics distributors. Unfortunately, upgrades to the circuit design have not been widely disseminated and therefore remain unknown to the great majority of researchers. Relatively recent studies using this technology only cite the original CAPMON design although modified versions of the apparatus are used (Chelazzi et al. 2001; Chelazzi et al. 1999; De Pirro et al. 1999a; De Pirro et al. 1999b; Morritt et al. 2007; Santini et al. 1999; Sarà and De Pirro 2011; Ungherese et al. 2008; Williams et al. 2011). Therefore, the aim of this paper is to disseminate widely the specific design of an IR sensor and corresponding amplification system, thus enabling a uniform method of data collection by a wide range of researchers. We also report the results of observational and experimental studies using previous versions of IR heartbeat sensors, further validating the technique as an effective way to measure heartbeat rates of intertidal invertebrates in both laboratory (Calosi et al. 2005; Marshall et al. 2011; Rovero et al. 2000; Spooner et al. 2007) and field experiments (Santini et al. 2000; Styrishave et al. 2003; Williams et al. 2005).

\section{Materials and procedures}

The sensors typically used with the IR method of heart rate measurement combine an IR emitter and an IR detector in a small package. Fixing the sensor to the exoskeleton of an animal, above its heart, allows IR light to pass through the shell of the animal and illuminate the heart and nearby circulatory vessels. Changes in the shape or volume of the circulatory structures during a heart contraction, or heartbeat, cause a change in the amount of IR light reflected from the animal's internal anatomy back to the IR detector. These changes in reflected IR light, transduced to changes in electrical current, are then electronically amplified and filtered, and processed by the software (Fig. 1).

The circuit board in the design presented here (Fig. 2) was produced on a two-layer printed circuit card (ExpressPCB Corp.). The power supply portion of the circuit (Fig. 2A) consists of a $6 \mathrm{~V}$ battery pack connected to a LM7805 fixed voltage regulator, which feeds the circuit with $5 \mathrm{~V}$. Two bypass capacitors (C1 and C2, with $1 \mu \mathrm{F}$ and $22 \mu \mathrm{F}$, respectively) are employed to improve supply voltage stability, and an LED (D1) indicates when the circuit is powered. This device uses a CNY70 (Vishay Intertechnologies) sensor (Fig. 2C), the same sensor as the original CAPMON system (1990). The sensor is connected to a thin, flexible wire (e.g., unshielded 30 AWG wirewrap wire, Digikey part K329-ND or shielded 30 AWG Pro Power 3027442, Newark part 98K8670), to minimize disturbance of the monitored animal. The other end of the wire connects to the main circuit via an RJ-11 connector (J1).

The signal conditioning circuit (Fig. 2B) is built around a single chip (LM 358) containing two identical high-gain operational amplifiers fed by the same power supply. A $1 \mu \mathrm{F}$ bypass capacitor (C7) at the LM 358's power input is used to further reduce power supply noise. The two noninverting amplification stages yield a maximum gain of $78 \mathrm{~dB}$ and are fitted with low-pass filters to reduce the amplification of unwanted high frequency electrical noise from nearby equipment or power lines. The combined cut-off frequency

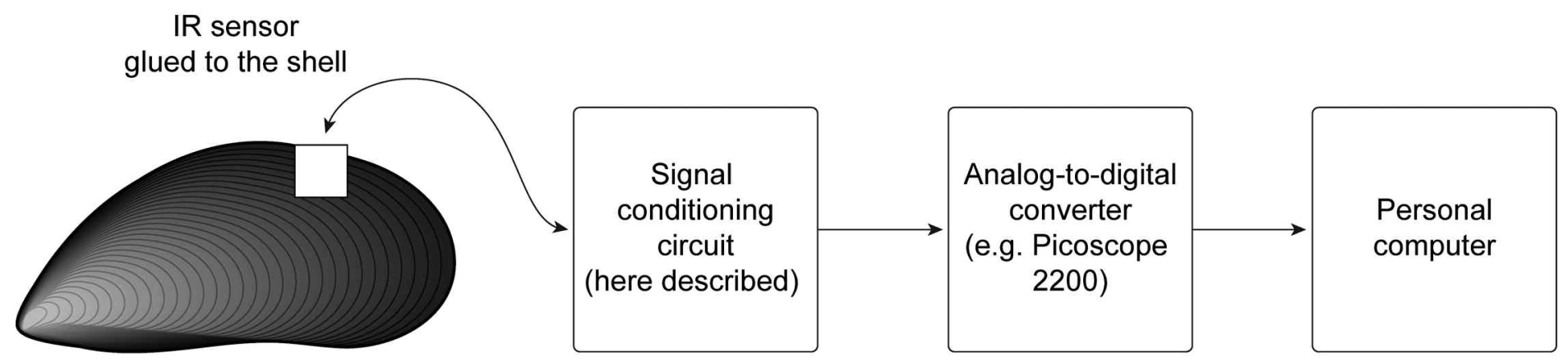

Analysed animal

Fig. 1. Flowchart of the heartbeat signal from the IR sensor to the data logging device. 
A

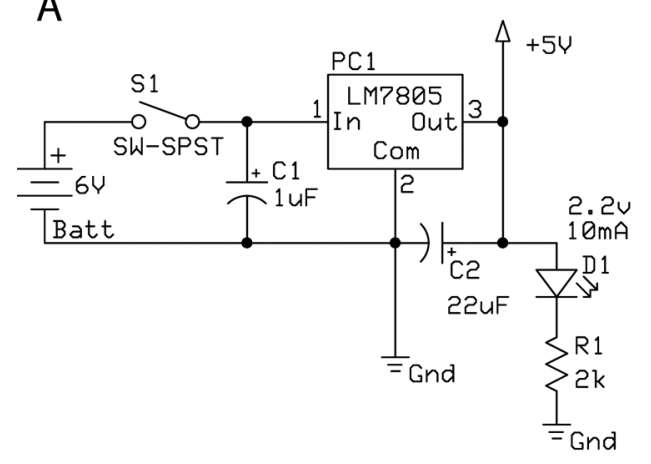

C

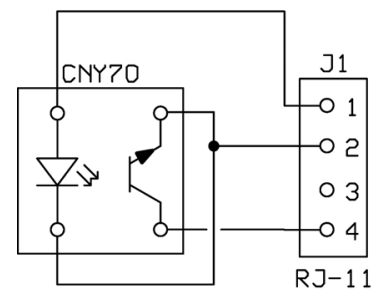

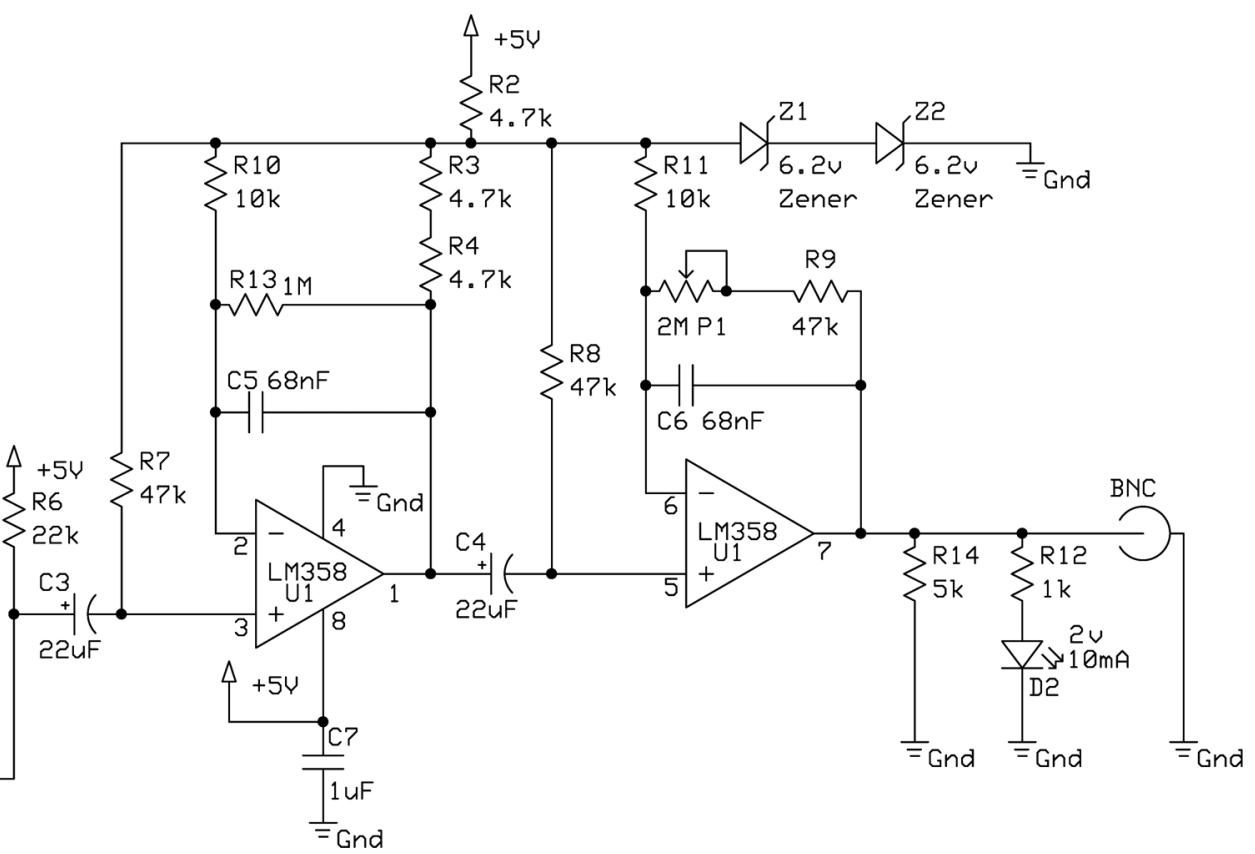

Fig. 2. Functional schematic diagram of IR cardiac sensing amplification circuit. See Table 1 for the Bill of Materials. Note chip LM358 (U1) has two operational amplifiers, so each is depicted with its pin connections.

is $2.2 \mathrm{~Hz}$ (at a $3 \mathrm{~dB}$ level), i.e., the maximum amplification is approximately 7900× for frequencies between $0.2 \mathrm{~Hz}$ and 1 $\mathrm{Hz}$, but at frequencies up to $3 \mathrm{~Hz}$ the amplification is still reasonable (gain calculated using LTspice IV software, www.linear.com). The potentiometer (P1) can be manually adjusted, reducing the overall amplification where needed. Two $22 \mu \mathrm{F}$ capacitors (C3 and C4) at the input of each amplifier filter out the DC component in the signal. Faster capacitors (e.g., 2.2 $\mu \mathrm{F})$ can also be used, but reduce the amplification of low frequencies and thus should not be used for animals with heart rates slower than approximately $1 \mathrm{~Hz}$. The diodes Z1 and Z2 control the bias voltage $(0.6 \mathrm{~V})$ on the amplification stages, and the LED D2, placed at the output of the second amplifier stage, flashes as pulses are received and amplified by the circuit. The amplified signal is outputted to a BNC connector, which can be used to connect the circuit to either an external oscilloscope or PC. The complete bill of materials (BOM) is provided in Table 1.

A PicoScope 2200 (Pico Technology) or USB-6009 (National Instruments) is used to convert the analog signal from the signal conditioning circuit to a digital format, which is then read and plotted on a PC running PicoScope 6 software (www.picotech.com) or NI LabView Signal Express (http://www.ni.com/labview/signalexpress/). Cardiac frequency is calculated using a spectral analysis procedure or manually by dividing the number of regular voltage oscillations by the amount of time recorded.

\section{Assessment}

In contrast with the CAPMON system, the signal conditioning circuit here described does not transform the analog signals from the IR sensor into square waves for automatic calculation of cardiac frequencies (Depledge and Andersen 1990; Depledge et al. 1996). The CAPMON system was originally intended for measuring heartbeat of decapod crustaceans, so the automatic counting feature was specific to typical decapod crustacean heartbeat patterns (Depledge and Andersen 1990). The benefit of collecting raw, non-square heartbeat signal waves is that animals can have unique heartbeat patterns that may otherwise be misinterpreted by an automatic counting circuit (Fig. 3).

The IR method is most easily used on arthropods and mollusks, as the exoskeletons of these animals provide the IR sensor a stable surface for attachment, enabling consistent measurements of each over time. Though this method and similar principles have been previously validated in crustaceans (Depledge and Andersen 1990) and bivalve mollusks (Haefner et al. 1996), we compared the reliability of the updated amplifier to heartbeat recordings made with the standard impedance method (Helm and Trueman 1967). Simultaneous heartbeat measurements were made in an adult Atlantic blue crab, Callinectes sapidus, using the IR method with our updated amplifier and the impedance method with the implantation of 30 gauge Teflon-coated magnet wire. Data from the two methods were collected as analog signals (impedance con- 
Table 1. Bill of Materials for the IR cardiac sensing amplification circuit. Digikey: www.digikey.com; Newark: www.newark.com.

\begin{tabular}{|c|c|c|c|c|c|}
\hline Reference & Type & Description & Manufacturer part nr & Digikey part $\mathrm{nr}$ & Newark part nr \\
\hline $\mathrm{R} 1$ & Resistor & $2 \mathrm{k} \Omega, 250 \mathrm{~mW}, 1 \%$ & CMF1/42001FLFTR & CMF502K0000FHEB & $40 \mathrm{M} 8448$ \\
\hline R5 & Resistor & $120 \Omega, 250 \mathrm{~mW}, 1 \%$ & MCMF0W4FF1200A50 & MFP-25BRD52-120R & $58 K 3804$ \\
\hline $\mathrm{R} 7, \mathrm{R} 8, \mathrm{R} 9$ & Resistor & $47 \mathrm{k} \Omega, 250 \mathrm{~mW}, 1 \%$ & MCMF0W4FF4702A50 & MFP-25BRD52-47K & $58 K 3860$ \\
\hline R6 & Resistor & $22 \mathrm{k} \Omega, 250 \mathrm{~mW}, 1 \%$ & MCMF0W4FF2202A50 & RNMF14FTC22K0 & $58 K 3829$ \\
\hline R10, R11 & Resistor & $10 \mathrm{k} \Omega, 250 \mathrm{~mW}, 1 \%$ & CMF1/41002FLFTR & MFP-25BRD52-10K & $40 \mathrm{M} 8391$ \\
\hline $\mathrm{R} 13$ & Resistor & $1 \mathrm{M} \Omega, 250 \mathrm{~mW}, 1 \%$ & HVR2500001004FR500 & MFR-25FRF-1M00 & $24 R 8876$ \\
\hline $\mathrm{R} 2, \mathrm{R} 3, \mathrm{R} 4$ & Resistor & $4.7 \mathrm{k} \Omega, 250 \mathrm{~mW}, 1 \%$ & MCMF0W4FF4701A50 & MFP-25BRD52-4K7 & $58 K 3858$ \\
\hline $\mathrm{R} 14$ & Resistor & $5 \mathrm{k} \Omega, 250 \mathrm{~mW}, 1 \%$ & MCMF0W4BB5001A50 & RN60D5001FB14 & $97 \mathrm{M} 6277$ \\
\hline $\mathrm{R} 12$ & Resistor & $1 \mathrm{k} \Omega, 250 \mathrm{~mW}, 1 \%$ & MCMF0W4FF3900A50 & MFP-25BRD52-1K & $58 K 3796$ \\
\hline P1 & Potentiometer & $2 \mathrm{M} \Omega, 0.5 \mathrm{~W}$ & $3299 \mathrm{~W}-1-205 \mathrm{LF}$ & 3299W-205LF-ND & $32 K 7942$ \\
\hline $\mathrm{C} 5, \mathrm{C} 6$ & Capacitor & $68 \eta F, 50$ V, 5\%, Metal Poly & BFC237022683 & 3012PH-ND & $95 C 1397$ \\
\hline $\mathrm{C} 2, \mathrm{C} 3, \mathrm{C} 4$ & Capacitor & $22 \mu \mathrm{F}, 50 \mathrm{~V}, 20 \%$, Electrolytic & ECA-1EM220 & P5149-ND & $58 \mathrm{~T} 1652$ \\
\hline $\mathrm{C} 1, \mathrm{C} 7$ & Capacitor & $1 \mu \mathrm{F}, 50 \mathrm{~V}, 20 \%$, Radial & ECA-1HM010I & P10421TB-ND & $38 \mathrm{~K} 1171$ \\
\hline D1 & Green LED & $3 \mathrm{~mm}, 568 \mathrm{~nm}, 2.2 \mathrm{~V}, 10 \mathrm{~mA}$ & WP3A8GD & 754-1217-ND & $93 K 6987$ \\
\hline D2 & Red LED & $5 \mathrm{~mm}, 623 \mathrm{~nm}, 2 \mathrm{~V}, 10 \mathrm{~mA}$ & LTL-10223W & 160-1087-ND & $93 K 6988$ \\
\hline PC1 & Voltage regulator & $5 \mathrm{~V}, 1 \mathrm{~A}$ & LM7805CT & LM7805CT-ND & $34 C 1092$ \\
\hline U1 & Dual op amp & $700 \mathrm{kHz}$ dual 8 DIP & LM358 & 296-9554-5-ND & $41 K 4888$ \\
\hline $\mathrm{Z1}, \mathrm{Z2}$ & Zener diode & $500 \mathrm{~mW}, 6.2 \mathrm{~V}, 5 \%$ & $1 \mathrm{~N} 753 \mathrm{~A}$ & - & $10 \mathrm{M} 6196$ \\
\hline BNC & BNC connector & $50 \mathrm{~W}$ & $31-5431-2010$ & ARF1065NW-ND & - \\
\hline j1 & RJ-11 plug & 4 conductor & $30-9910$ & - & $30-9910$ \\
\hline $\mathrm{J} 2$ & $\mathrm{RJ}-11$ connector & 4 pin & $5520250-2$ & A31405-ND & - \\
\hline CNY70 & IR sensor & $950 \mathrm{~nm}$ emitter/transducer & CNY70 & 751-1025-ND & $95 B 4223$ \\
\hline
\end{tabular}

verted by UFI Impedance Converter, UFI) by a single data acquisition system (Sable Systems UI-2 Data Acquisition Interface, Sable Systems International) at a sampling rate of $5 \mathrm{~Hz}$. Heartbeat signals from the impedance and IR methods showed the same heartbeat pattern and frequency (Fig. 4).

The placement of the sensor has a strong effect on the quality of the heartbeat signal (see "Discussion" for details). In crabs there are markings on the carapace just dorsal to the heart, facilitating effective placement of the IR sensor. However, in a bivalve mollusk, it can be more difficult to place the sensor effectively over the heart. Using the IR method on the bivalve Septifer virgatus (shell length $=3 \mathrm{~cm}$ ), we compared the quality of heartbeat signals collected at various locations around the valves of the mussel (Fig. 5). The heartbeat signals at an optimal position (position B) had amplitudes twice that of signals from a poorly positioned sensor, and more importantly, a regular repeating pattern. Signals with better quality for $S$. virgatus were typically found next to the mid-dorsal posterior hinge area of the valves, although each was slightly different. Shell curvature and thickness, as well as the whole animal size, certainly contribute to variations among conspecifics, so other species should be evaluated in a similar manner to find the best location for sensor placement to detect heart contractions. This evaluation can be performed by observing real-time changes in signal quality at different locations, even before bonding the sensor to the animal. Uncertainty in the placement of the sensor does not necessarily mean clear heartbeat signals are diffi- cult to obtain. For example, limpets of the genus Patella are fairly resilient to handling disturbance, and it is possible to identify the most effective sensor placement by simply pressing the sensor against the limpet's shell and holding the apparatus still for the whole measurement. This method is not useful for organisms that exhibit irregular heartbeat patterns in response to handling disturbance. Conversely, with proper cleaning of the area where the sensor is to be attached and by using a strong bonding agent, a durable yet unintrusive system can be assembled, which enables longer experiments to be performed. For example, Fig. 6 shows a week's worth of heartbeat data obtained from a single Patella vulgata.

\section{Discussion}

In general, the IR sensor amplifier modifications described in this article are a simplification of the original CAPMON system. In lieu of an automatic triggering function that calculates average heartbeat rates, the updated amplifier preserves the raw signal after amplifying it to a specific voltage scale. Maintaining the true shape of the wave is beneficial because each organism is likely to exhibit a unique heartbeat pattern that may otherwise be misinterpreted by an automatic counting circuit, like that seen with the CAPMON system. This is particularly important for animals that have irregular heartbeat rates (Depledge et al. 1996).

Noise on the IR heartbeat signal in combination with irregular or extremely slow heartbeats can create a heartbeat signal 

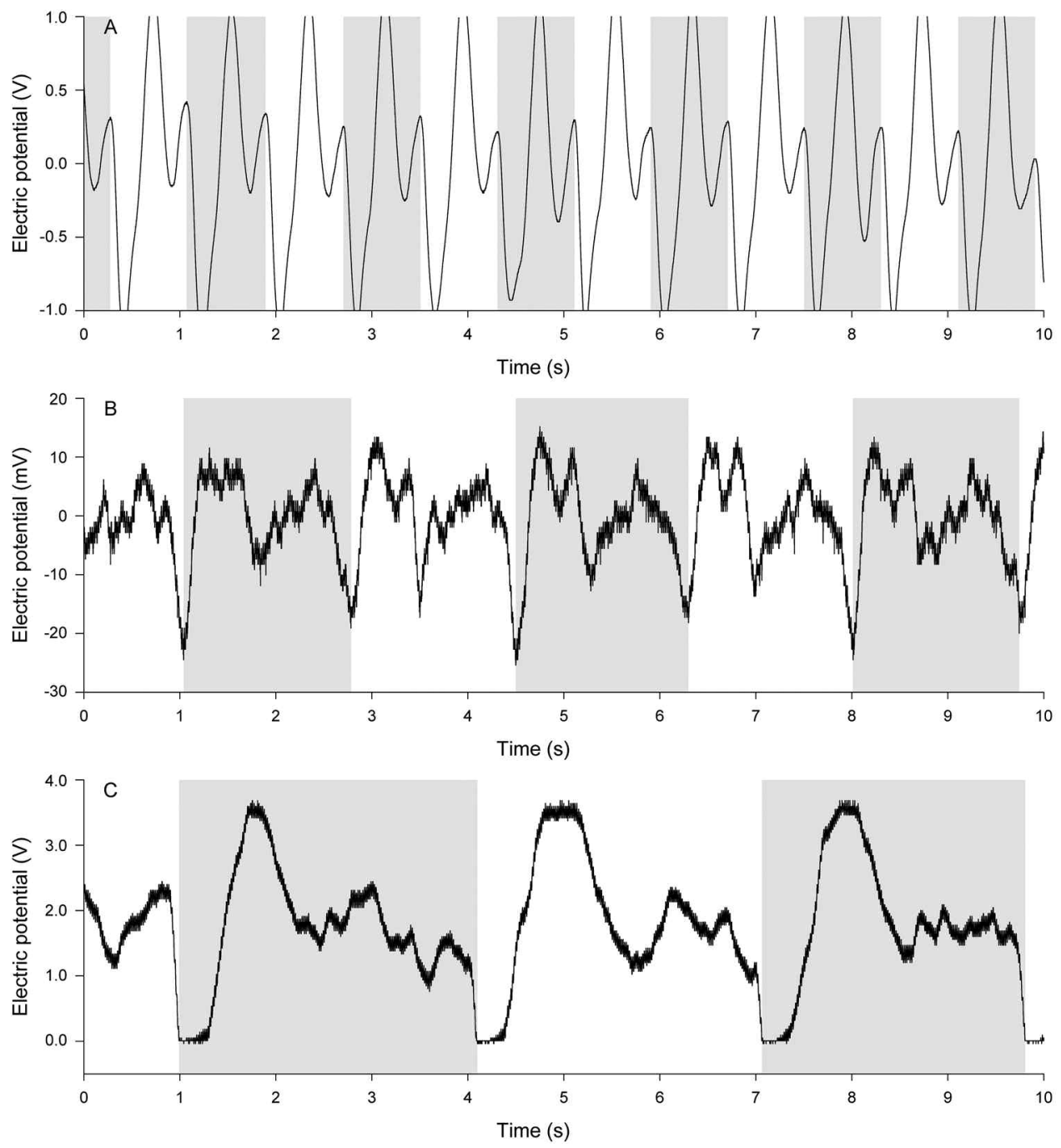

Fig. 3. Unfiltered heartbeat signals of the limpet Cellana grata (A), the mussel Septifer virgatus (B), and the mud crab Panopeus herbstii (C). The scale of the $y$-axes varies among graphs. Note that depending on the species (and also on the sensor placement), the shape of the curve may feature multiple peaks per heartbeat. Signal noise also varies among the graphs, potentially caused by electrical noise from the oscilloscope. Therefore, automatic peak counting may not give accurate results. Shaded areas are provided to facilitate signal comparison.

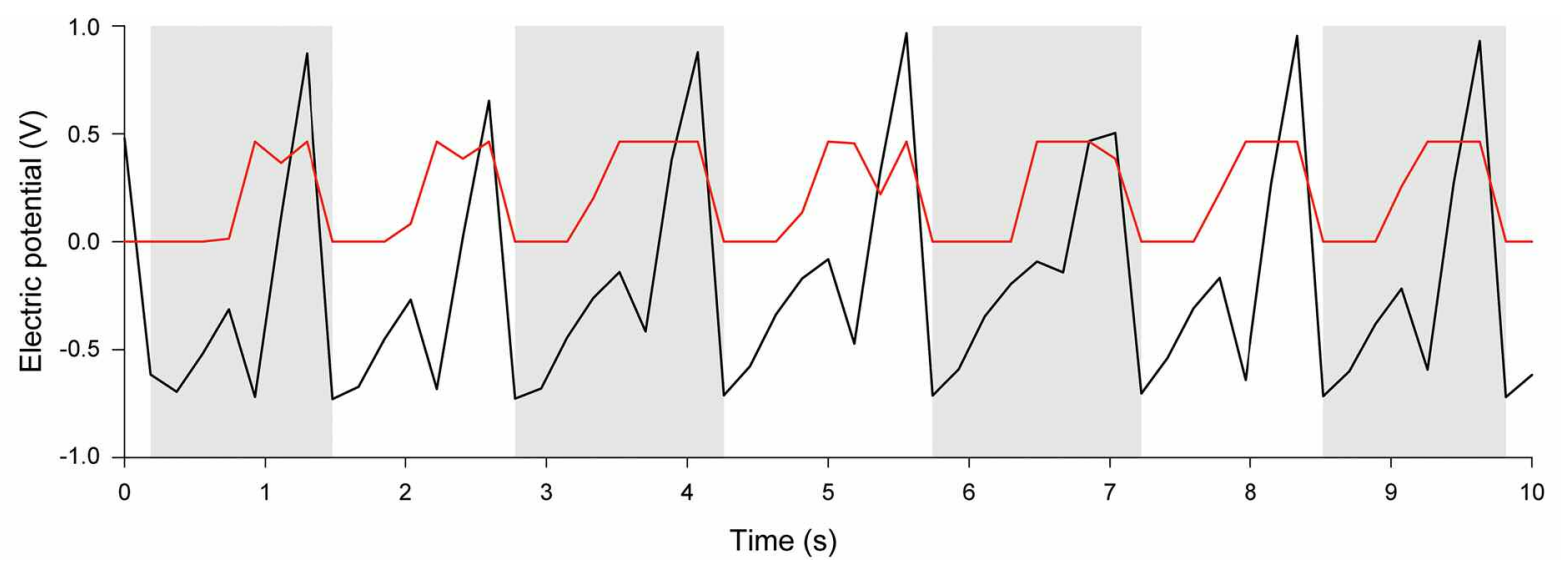

Fig. 4. Heartbeat patterns of an Atlantic blue crab (Callinectes sapidus) measured simultaneously with the standard impedance method (black line) and with IR sensors (red line). Both lines show seven complete heartbeats in the $10 \mathrm{~s}$ interval. Shaded areas are provided to facilitate signal comparison. 

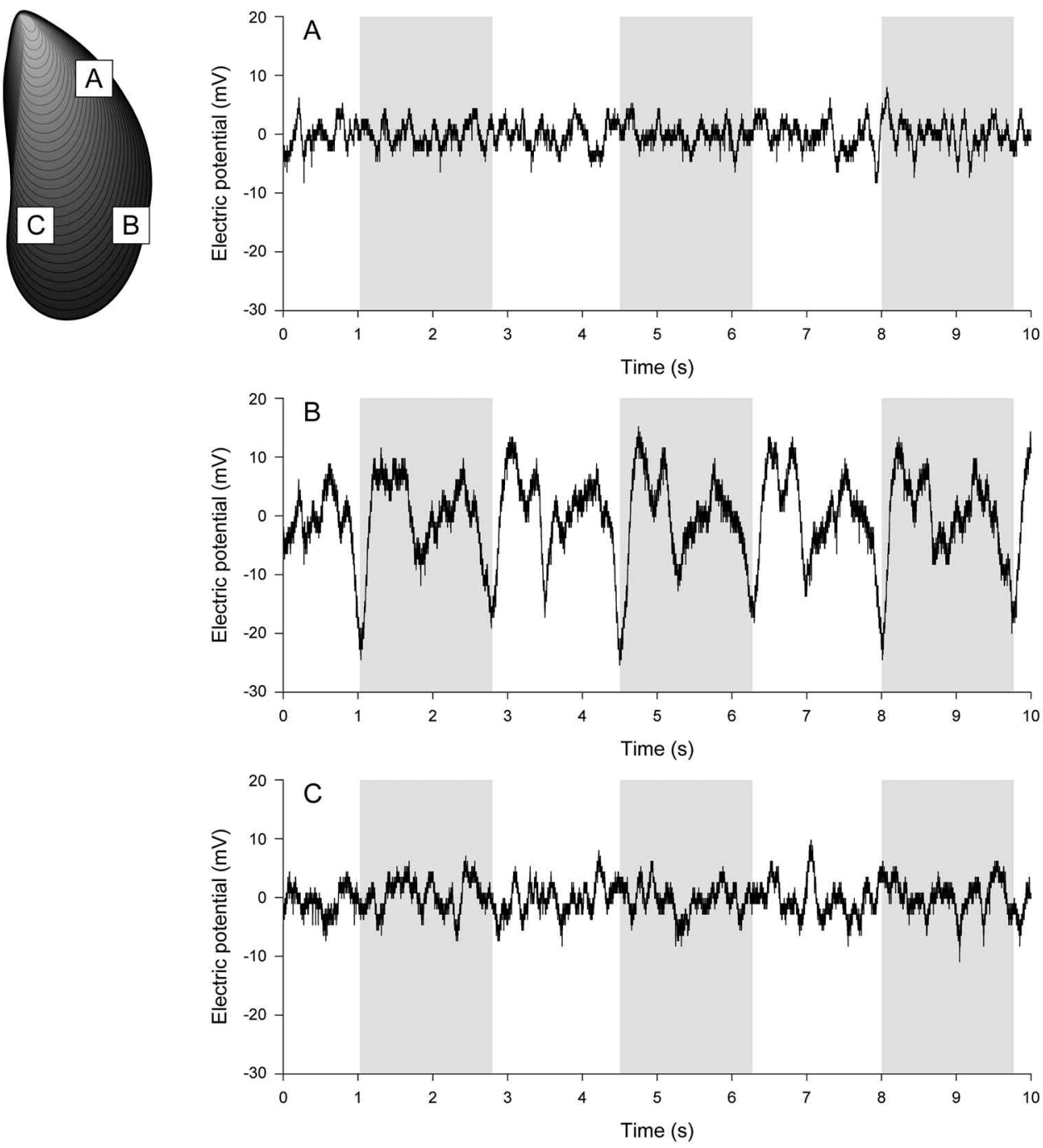

Fig. 5. Variation in measurements of the heartbeat signal of the mussel Septifer virgatus with the IR sensor placed on three regions on the shell (A, B, and C). Shaded sections are provided to facilitate comparison of signals.

too complex for automatic analysis (e.g., FFT analysis, periodogram) and often requires heartbeat frequencies to be identified and counted manually. In this context, it is important to clarify that the IR method is primarily designed to measure heartbeat frequency and not signal amplitude. Sensor placement must therefore be optimized (see above) to obtain the best signal quality-i.e., cyclic fluctuations in voltage can be identified, the number occurring over a continuous period can be determined, and rate can then be calculated (Fig. 7). Because even the continuous monitoring of one animal without repositioning the sensor can reveal changes in amplitude and shape of the signal (e.g., Fig. 7A-D), one cannot use the amplitude and shape of the signal to assess cardiac function. Additionally, preserving heartbeat signals in raw format may allow further analyses to be made, such as the identification of bradycardia or periods of no heartbeat (Chelazzi et al. 2001; De Pirro et al. 1999b; Marshall et al. 2004).
The sensor component of the system described here has been modified to detect heartbeat of smaller invertebrates $(<1$ $\mathrm{cm}$ ) by direct contact of the IR sensor (Calosi et al. 2003) or indirectly by placing the animal within the confinement of an aluminum foil bag (Van Aardt and Vosloo 1996). It can also be modified to measure cardiac activity of animals under simulated hyperbaric conditions (Robinson et al. 2009). Tailoring IR sensors to particular species allows the IR method to be fairly reliable, robust, flexible, and most important, noninvasive. The application of this method to other organisms has likely been limited by the availability and awareness of the method, rather than the compatibility of the sensor with the study organisms. Apart from the amplification circuitry, further simple modifications to the hardware can expand and enhance the use of the system in physiology and ecology studies. For example, finer gauge wire for the entire length between the amplifier and the IR sensor reduces movement 


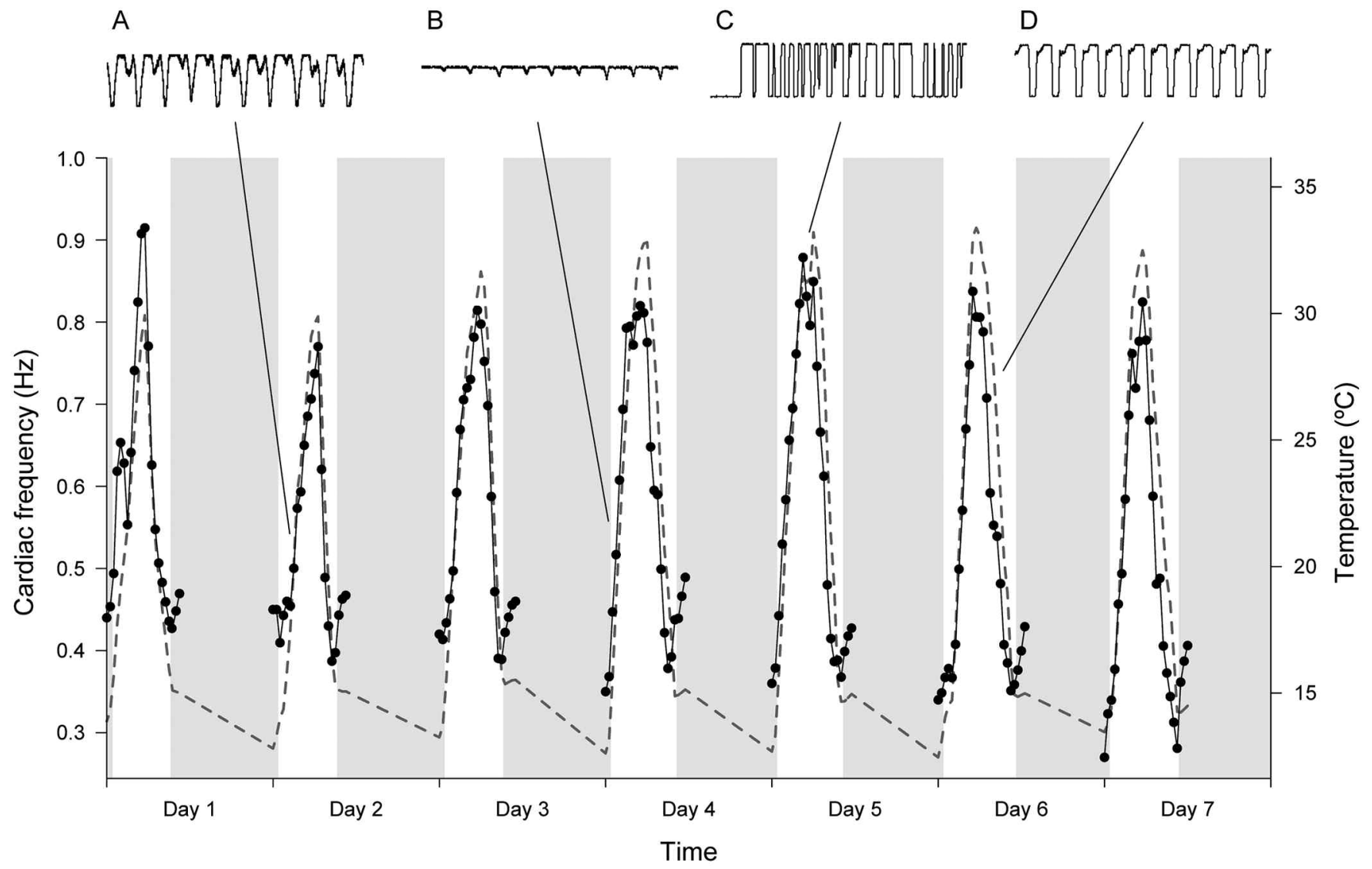

Fig. 6. Cardiac frequency of a china limpet (Patella vulgata) exposed to $7 \mathrm{~d}$ of simulated tides under laboratory conditions. The sensor was attached to the animal during the acclimation period, and remained in place for the whole experiment. Heartbeat was measured every 30 min in the period between $1 \mathrm{~h}$ before the low tide and $2 \mathrm{~h}$ after the low tide. Closed circles show heartbeat measurements. The dashed gray line shows the thermal profile to which the animal was exposed during the experiment. The vertical shaded regions indicate periods of immersion, and the vertical unshaded regions indicate periods of emersion. Inserts A-D show the heartbeat signal recorded at the 4 different times indicated, illustrating that even with considerable variability in signal shape and amplitude, it is still possible to obtain comparable heartbeat rates. Signal amplitude was $2.5 \mathrm{~V}$ in $\mathrm{A}, \mathrm{C}$, and D and $1.3 \mathrm{~V}$ in $\mathrm{B}$.

restriction when measuring heartbeat rate in mobile or burrowing animals (shielded 30 AWG Pro Power 3027442, Newark part 98K8670), we commonly use sensor leads of $2 \mathrm{~m}$ without detectable signal attenuation; smaller and flatter IR sensors, e.g., reflective optical sensor TCRT1010 (Vishay Intertechnologies, Inc.), facilitate measuring heartbeat rate in smaller organisms or in burrowing organisms; multichannel analog data loggers, e.g., National Instruments USB-6009 (National Instruments Corp.), allow for multiple individuals to be monitored concurrently. The circuit described here has to be printed in a PCB board and manually assembled, using the parts listed in Table 1, which might be a serious obstacle to researchers unfamiliar or un-equipped to work with electronics. Alternatively, electrical contractors can easily construct the circuit boards and sensors for this system at relatively low cost (e.g., AMP-3, Newshift Lda). These professionally built systems have the additional advantage of improved voltage stability, industrial quality assemblage, and sturdy connectors.
Limitations to the IR method may be encountered when recording the heartbeat of active animals. Distortions to the signal can be caused by body movements such as foot movement in small littorinid snails, radula movement in gastropods, and siphon activity in bivalves. Foot movement during locomotion or radula movement while feeding can create a signal that is momentarily greater than the signal of the true heartbeat. Detecting foot movement may be difficult to avoid in smaller active gastropods, but disturbance from the radula movement can be minimized by placing the IR sensor on an alternative location on the shell where a heartbeat signal is still detectable. To some extent this is also the case for the electrical impedance method, since the measurement of impedance variation between two points in the organism's body is also susceptible to movement artifacts.

Further limitations may be encountered when using the IR method due to the penetration and detection of the IR light. Infrared light penetration of the shell depends on shell thickness and structure. Therefore, this method may not work well for ani- 

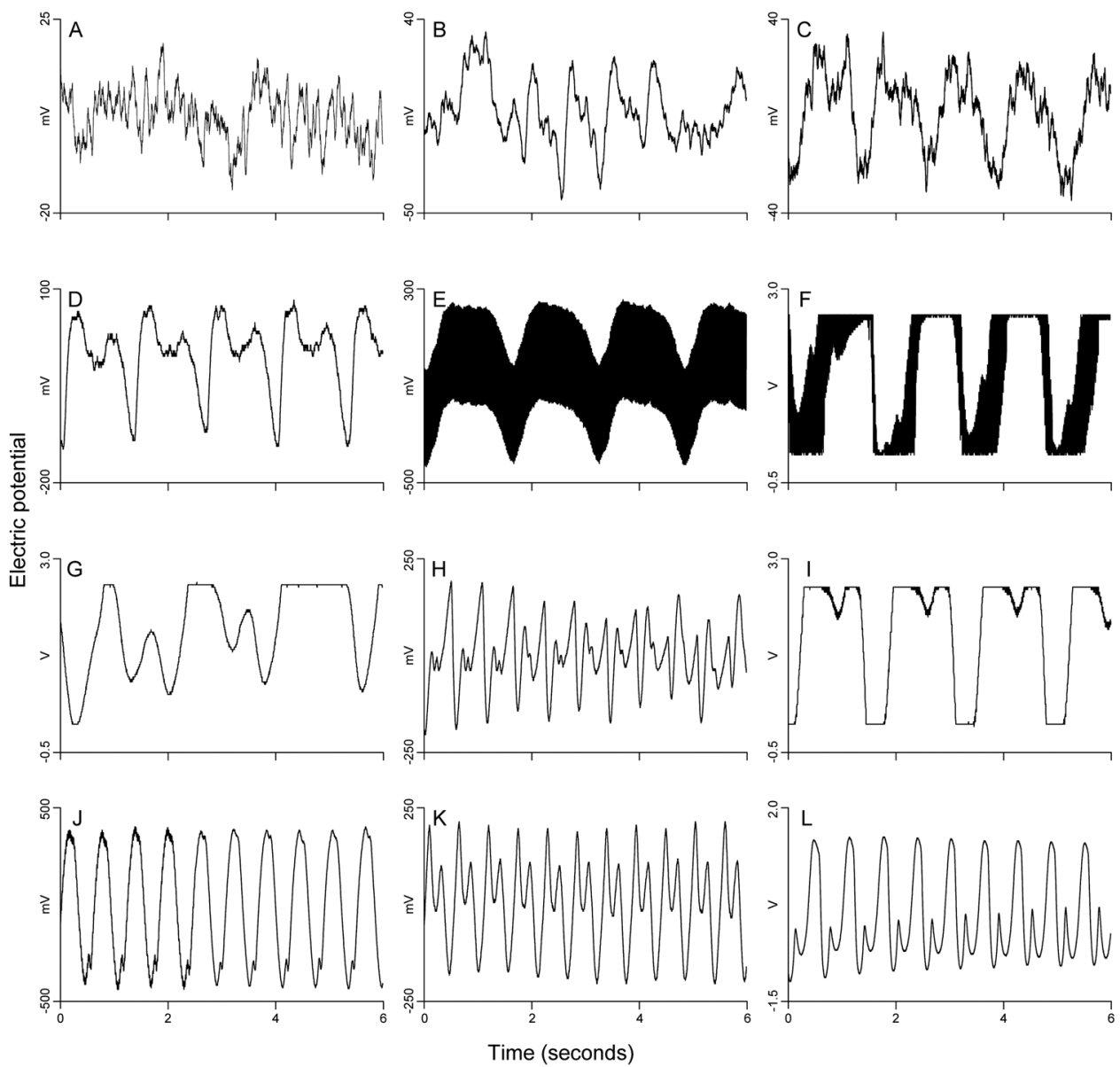

Fig. 7. Examples of heartbeat signals of $P$. vulgata recorded under various laboratory conditions. Signal quality can be degraded by numerous factors: signal below amplification power $(A, B)$, poor insulation of sensor wiring $(C)$, presence of electronic noise $(E$, $F)$, sub-optimal placement of the sensor $(G)$, or movement of internal organs other than the heart (possibly $H)$. Such conditions can render the signal useless (A) or almost useless (B), but as long as a regular repeating pattern can be found the signal has sufficient quality for heartbeat rate to be calculated (C). Signals like that in $\mathrm{G}$ may require additional recordings so they can be more safely interpreted. Better quality signals are usually composed of two crests per heartbeat, with crests having equal or very different amplitudes (D, H-I, K-L, but see J). Clipping occurs when the signal voltage exceeds the circuit output range ( $F, G, I)$, and results in a flat top or bottom in the signal; this situation is fairly common and does not necessarily indicate a poor signal. It can, however, be avoided by tuning the potentiometer P1 in the circuit (see Fig. 2).

mals with extremely thick shells, though the upper limit of thickness has not been established. Detecting a heartbeat signal may be difficult if changes in ambient IR light cause signal fluctuations that mask the heartbeat. This ambient IR light problem can be avoided by creating a seal around the junction of the IR sensor and the animal's shell to block out ambient IR light.

The compact design and relative simplicity of the amplifier circuit and sensor described herein should facilitate more in situ studies of marine invertebrates, particularly those in the intertidal zone. Use of a computer or oscilloscope that can be enclosed in water-proof containers or transported quickly to measure heartbeats of animals in wave-exposed parts of a shore (Santini et al. 2000; Williams et al. 2005) complements the portable design of the amplifier circuit and sensor. The noninvasive nature of the sensor promotes longer term physiological studies (Fig. 6) and behavioral studies (Curtis et al.
2000; Rovero et al. 2000; Santini et al. 2002) for many species that would otherwise be hindered by the disturbance from the implantation of electrodes associated with the impedance method of heartbeat measurement. Along the same lines, marine microbiological and immunological studies requiring sterile methods for measuring physiological responses (Burnett et al. 2006) can also benefit from the application of noninvasive sensing.

It is the authors' hope that the integration of taxonomically diverse physiological and ecological data, as enabled by the widespread compatibility of the IR method, can provide more comprehensive surveys of ecosystem health (Galloway et al. 2004; Hagger et al. 2009) in response to environmental stressors (Calosi et al. 2005; Chelazzi et al. 2001; Williams et al. 2011) or pollution (Bloxham et al. 1999; Curtis et al. 2001; Marshall et al. 2004). 


\section{References}

Bayne, B. L., C. J. Bayne, T. C. Carefoot, and R. J. Thompson. 1976. The physiological ecology of Mytilus californianus Conrad 1. Metabolism and energy balance. Oecologia 22:211-228 [doi:10.1007/BF00344793].

Bini, G., and G. Chelazzi. 2006. Acclimatable cardiac and ventilatory responses to copper in the freshwater crayfish Procambarus clarkii. Comp. Biochem. Physiol. C 144:235-241 [doi:10.1016/j.cbpc.2006.08.014].

Bloxham, M. J., P. J. Worsfold, and M. H. Depledge. 1999. Integrated biological and chemical monitoring: In situ physiological responses of freshwater crayfish to fluctuations in environmental ammonia concentrations. Ecotoxicology 8:225-237 [doi:10.1023/A:1026400532305].

Braby, C. E., and G. N. Somero. 2006. Following the heart: temperature and salinity effects on heart rate in native and invasive species of blue mussels (genus Mytilus). J. Exp. Biol. 209:2554-2566 [doi:10.1242/jeb.02259].

Burnett, L. E., J. D. Holman, D. D. Jorgensen, J. L. Ikerd, and K. G. Burnett. 2006. Immune defense reduces respiratory fitness in Callinectes sapidus, the Atlantic blue crab. Biol. Bull. 211:50-57 [doi:10.2307/4134577].

Calosi, P., G. Chelazzi, and A. Ugolini. 2003. Optocardiographic recording of heart rate in Talitrus saltator (Amphipoda : Talitridae). Physiol. Entomol. 28:344-348 [doi:10.1111/j.1365-3032.2003.00348.x].

___ A. Ugolini, and D. Morritt. 2005. Physiological responses to hyposmotic stress in the supralittoral amphipod Talitrus saltator (Crustacea : Amphipoda). Comp. Biochem. Physiol. A 142:267-275 [doi:10.1016/j.cbpb. 2005.06.012].

Chelazzi, G., G. A. Williams, and D. R. Gray. 1999. Field and laboratory measurement of heart rate in a tropical limpet, Cellana grata. J. Mar. Biol. Assoc. U.K. 79:749-751 [doi:10.1017/S0025315498000915].

—, M. De Pirro, and G. A. Williams. 2001. Cardiac responses to abiotic factors in two tropical limpets, occurring at different levels of the shore. Mar. Biol. 139:10791085 [doi:10.1007/s002270100603].

——, and - 2004. Different cardiac response to copper in limpets from metal polluted and clean shores of Hong Kong. Mar. Environ. Res. 58:83-93 [doi:10.1016/ j.marenvres.2004.01.001].

Curtis, T. M., R. Williamson, and M. H. Depledge. 2000. Simultaneous, long-term monitoring of valve and cardiac activity in the blue mussel Mytilus edulis exposed to copper. Mar. Biol. 136:837-846 [doi:10.1007/s002270000297].

— - , and 2001. The initial mode of action of copper on the cardiac physiology of the blue mussel, Mytilus edulis. Aquat. Toxicol. 52:29-38 [doi:10.1016/S0166445X(00)00135-1].

De Pirro, M., S. Cannicci, and G. Santini. 1999a. A multi-factorial experiment on heart rate variations in the intertidal crab Pachygrapsus marmoratus. Mar. Biol. 135:341-345 [doi:10.1007/s002270050632].

—, G. Santini, and G. Chelazzi. 1999b. Cardiac responses to salinity variations in two differently zoned Mediterranean limpets. J. Comp. Physiol. B 169:501-506 [doi:10.1007/s003600050248].

Depledge, M. H., and B. B. Andersen. 1990. A computer-aided physiological monitoring system for continuous, long-term recording of cardiac activity in selected invertebrates. Comp. Biochem. Physiol. A 96:473-477 [doi:10.1016/03009629(90)90664-E].

—, A. K. Lundebye, T. Curtis, A. Aagaard, and B. B. Andersen. 1996. Automated interpulse-duration assessment (AIDA): A new technique for detecting disturbances in cardiac activity in selected macroinvertebrates. Mar. Biol. 126:313-319 [doi:10.1007/BF00347455].

Galloway, T. S., and others. 2004. A multibiomarker approach to environmental assessment. Environ. Sci. Technol. 38:1723-1731 [doi:10.1021/es030570+].

Haefner, P. A., B. Sheppard, J. Barto, E. Mcneil, and V. Cappellino. 1996. Application of ultrasound technology to molluscan physiology: Noninvasive monitoring of cardiac rate in the blue mussel, Mytilus edulis Linnaeus, 1758. J. Shellfish Res. 15:685-687.

Hagger, J. A., T. S. Galloway, W. J. Langston, and M. B. Jones. 2009. Application of biomarkers to assess the condition of European Marine Sites. Environ. Pollut. 157:2003-2010 [doi:10.1016/j.envpol.2009.02.038].

Halldórsson, H. P., M. De Pirro, C. Romano, J. Svavarsson, and G. Sarà. 2008. Immediate biomarker responses to benzo a pyrene in polluted and unpolluted populations of the blue mussel (Mytilus edulis L.) at high-latitudes. Environ. Intern. 34:483-489 [doi:10.1016/j.envint.2007.11.002].

Helm, M. M., and E. R. Trueman. 1967. The effect of exposure on the heart rate of the mussel, Mytilus edulis L. Comp. Biochem. Physiol. 21:171-177 [doi:10.1016/0010-406X(67) 90126-0].

Logan, C. A., L. E. Kost, and G. N. Somero. 2012. Latitudinal differences in Mytilus californianus thermal physiology. Mar. Ecol. Prog. Ser. 450:93-105 [doi:10.3354/meps09491].

Marshall, D. J., R. Peter, and S. L. Chown. 2004. Regulated bradycardia in the pulmonate limpet Siphonaria (Gastropoda : Mollusca) during pollutant exposure: implication for biomarker studies. Comp. Biochem. Physiol. A 139:309316 [doi:10.1016/j.cbpb.2004.09.014].

, Y. W. Dong, C. D. Mcquaid, and G. A. Williams. 2011. Thermal adaptation in the intertidal snail Echinolittorina malaccana contradicts current theory by revealing the crucial roles of resting metabolism. J. Exp. Biol. 214:3649-3657 [doi:10.1242/jeb.059899].

Morritt, D., K. M. Y. Leung, M. De Pirro, C. Yau, T. C. Wai, and G. A. William. 2007. Responses of the limpet, Cellana grata (Gould 1859), to hypo-osmotic stress during simulated tropical, monsoon rains. J. Exp. Mar. Biol. Ecol. 352:78-88 
[doi:10.1016/j.jembe.2007.07.002].

Nicholson, S. 2002. Ecophysiological aspects of cardiac activity in the subtropical mussel Perna viridis (L.) (Bivalvia : Mytilidae). J. Exp. Mar. Biol. Ecol. 267:207-222 [doi:10.1016/S0022-0981(01)00362-8].

Pickens, P. E. 1965. Heart rate of mussels as a function of latitude, intertidal height, and acclimation temperature. Physiol. Zool. 38:390-405.

Robinson, N. J., S. Thatje, and C. Osseforth. 2009. Heartbeat sensors under pressure: a new method for assessing hyperbaric physiology. High Pressure Res. 29:422-430 [doi:10.1080/ 08957950903076398].

Rovero, F., R. N. Hughes, and C. Chelazzi. 1999. Cardiac and behavioural responses of mussels to risk of predation by dogwhelks. Anim. Behav. 58:707-714 [doi:10.1006/anbe. 1999.1176].

, R. N. Hughes, N. M. Whiteley, and G. Chelazzi. 2000. Estimating the energetic cost of fighting in shore crabs by noninvasive monitoring of heartbeat rate. Anim. Behav. 59:705-713 [doi:10.1006/anbe.1999.1353].

Santini, G., M. De Pirro, and G. Chelazzi. 1999. In situ and laboratory assessment of heart rate in a Mediterranean limpet using a noninvasive technique. Physiol. Biochem. Zool. 72:198-204 [doi:10.1086/316656].

, G. A. Williams, and G. Chelazzi. 2000. Assessment of factors affecting heart rate of the limpet Patella vulgata on the natural shore. Mar. Biol. 137:291-296 [doi:10.1007/ s002270000339].

_, T. Bianchi, and G. Chelazzi. 2002. Metabolic responses to food deprivation in two limpets with different foraging regimes, revealed by recording of cardiac activity. J. Zool. 256:11-15 [doi:10.1017/S095283690200002X].

Sarà, G., and M. De Pirro. 2011. Heart beat rate adaptations to varying salinity of two intertidal Mediterranean bivalves: The invasive Brachidontes pharaonis and the native Mytilaster minimus. Ital. J. Zool. 78:193-197 [doi:10.1080/1125 0001003657360].

Somero, G. N. 2002. Thermal physiology and vertical zonation of intertidal animals: Optima, limits, and costs of living. Integr. Comp. Biol. 42:780-789 [doi:10.1093/icb/42.4.780].

Spooner, E. H., R. A. Coleman, and M. J. Attrill. 2007. Sex differences in body morphology and multitrophic interactions involving the foraging behaviour of the crab Carcinus maenas. Mar. Ecol. Evol. Persp. 28:394-403.

Stillman, J. H., and G. N. Somero. 1996. Adaptation to temperature stress and aerial exposure in congeneric species of intertidal porcelain crabs (genus Petrolisthes): Correlation of physiology, biochemistry and morphology with vertical distribution. J. Exp. Biol. 199:1845-1855.

Styrishave, B., O. Andersen, and M. H. Depledge. 2003. In situ monitoring of heart rates in shore crabs Carcinus maenas in two tidal estuaries: Effects of physico-chemical parameters on tidal and diel rhythms. Mar. Freshw. Behav. Physiol. 36:161-175 [doi:10.1080/10236240310001603215].

Ungherese, G., V. Boddi, and A. Ugolini. 2008. Eco-physiology of Palaemonetes antennarius (Crustacea, Decapoda): the influence of temperature and salinity on cardiac frequency. Physiol. Entomol. 33:155-161 [doi:10.1111/j.1365-3032.20 08.00620.x].

Van Aardt, W. J., and A. Vosloo. 1996. Modifications to an optocardiographic method for measurement of heart rate in a range of invertebrate species. South Afr. J. Zool. 31:97100.

Williams, G. A., M. De Pirro, K. M. Y. Leung, and D. Morritt. 2005. Physiological responses to heat stress on a tropical shore: the benefits of mushrooming behaviour in the limpet Cellana grata. Mar. Ecol. Prog. Ser. 292:213-224 [doi:10.3354/meps292213].

, and others. 2011. Come rain or shine: the combined effects of physical stresses on physiological and proteinlevel responses of an intertidal limpet in the monsoonal tropics. Funct. Ecol. 25:101-110 [doi:10.1111/j.13652435.2010.01760.x].

Submitted 19 September 2012 Revised 28 November 2012 Accepted 10 February 2013 